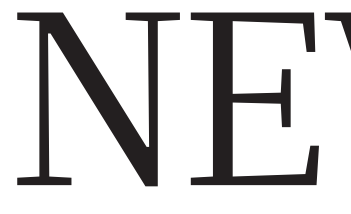

INFECTIOUS DISEASE Deadly tick-borne virus spreads in East Asia p.282
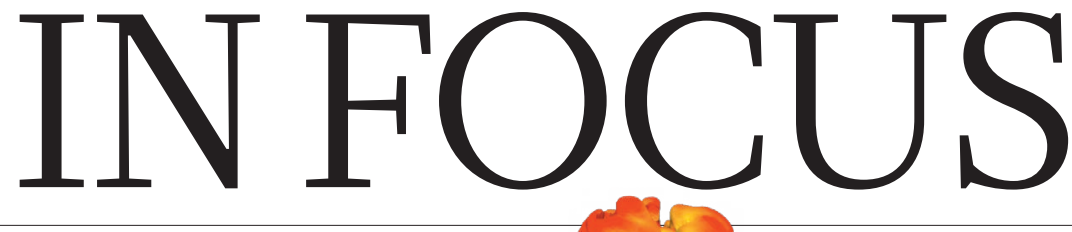

CHEMICAL WEAPONS Attacks

ENVIRONMENT African nations gear up to collect air-pollution data $\mathbf{p} .284$ give impetus to boosting forensic capacity $\mathbf{p . 2 8 5}$
ASTROPHYSICS How to blow

up a star: the science of supernova simulation $\mathbf{p . 2 8 7}$

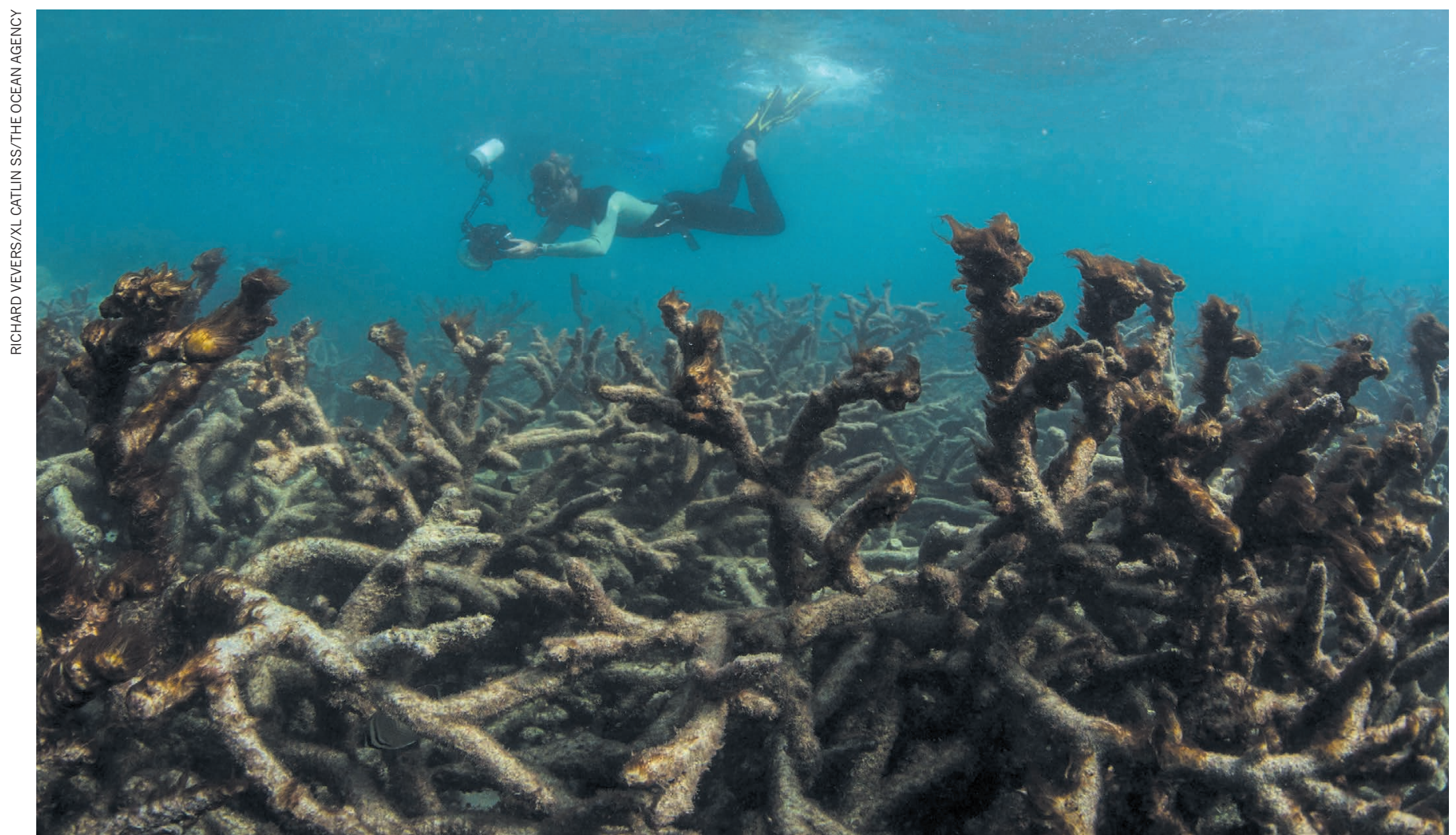

Heat stress and bleaching — the loss of symbiotic algae — killed many corals in Australia's Great Barrier Reef after the 2016 crisis.

\title{
ECOLOGY
}

\section{Great Barrier Reef saw huge losses from 2016 heatwave}

\section{One-third of the system's reefs were transformed after bleaching triggered by warmth.}

\section{BY QUIRIN SCHIERMEIER}

$\mathrm{E}$

xtreme heat in 2016 damaged Australia’s Great Barrier Reef much more substantially than initial surveys indicated, according to ongoing studies that have tracked the health of the coral treasure. The heatwave caused massive bleaching of the corals that captured worldwide attention.

In a paper published on 18 April in Nature, researchers report ${ }^{1}$ that severe bleaching on an unprecedented scale triggered mass death of corals. This drastically changed the species composition of almost one-third of the 3,863 individual reefs that comprise the Great Barrier Reef.

The world's largest coral reef is unlikely to recover soon. The damage is a harbinger of what a warmer future might hold for a wealth of tropical reef ecosystems, says lead study author Terry Hughes, director of the coral-reef centre at James Cook University in Townsville, Australia. "If we fail to curb climate change, and global temperatures rise far above $2^{\circ} \mathrm{C}$ [above the pre-industrial level], we will lose the benefits they provide to hundreds of millions of people."

\section{FATAL LOSS}

Hughes and his team of ecologists closely examined the 2,300-kilometre-long Great Barrier Reef after the 2016 heatwave. Extensive aerial surveys revealed widespread coral bleaching between March and April 2016. This phenomenon occurs when excessive heat kills or expels algae called $\downarrow$ 
- zooxanthellae, which have a symbiotic relationship with reef-building corals. The algae provide the corals with energy and nutrients from photosynthesis; without them, the corals often die.

But to gauge the full extent of heat damage, Hughes's team conducted morecomprehensive underwater surveys of coral mortality, both at the peak of the observed bleaching in March and April, and again eight months later.

Many corals - especially those in the northern third of the reef - died immediately from heat stress. Others were killed more slowly, after their algal partners were expelled. The composition of coral assemblages on hundreds of individual reefs changed radically within just a few months of the heatwave. On severely bleached reefs, fast-growing coral species - which have complex shapes that provide important habitats - were replaced by slower-growing groups that shelter a lessdiverse community.

"The study paints a bleak picture of the sheer extent of coral loss on the Great Barrier Reef," says Nick Graham, a marine ecologist at Lancaster University, UK. Approximately onethird of the world's coral reefs were affected by bleaching in 2016. On the Great Barrier Reef, less than $10 \%$ of reefs escaped with no bleaching (see 'Bleached reef'), compared with more than $40 \%$ in previous bleaching events studied.

"It is now critical to understand how governance and local management can maximize recovery between recurrent heatwaves," Graham says.

Tim McClanahan, a conservation zoologist

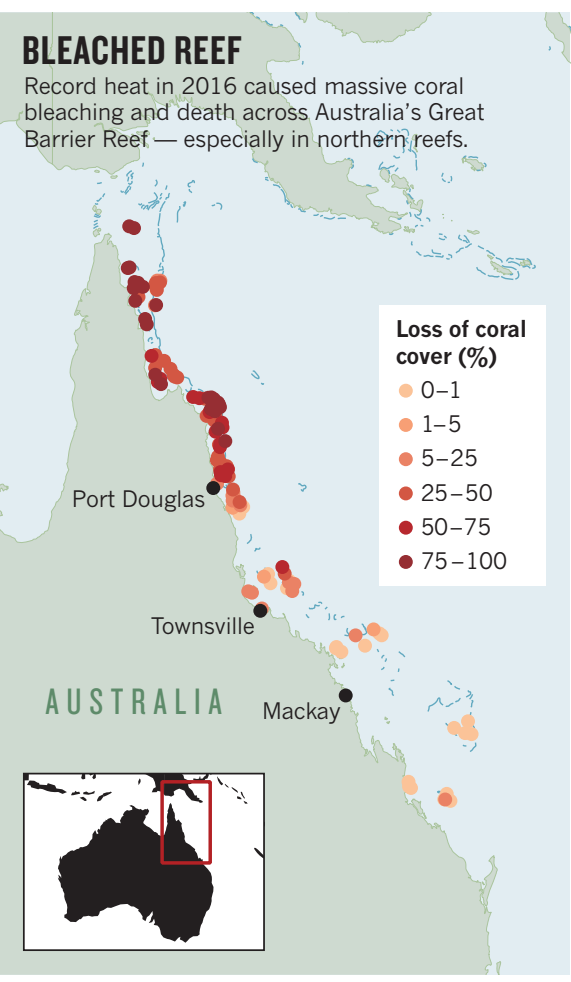

at the Wildlife Conservation Society in Mombasa, Kenya, says the study's findings might not predict how other reefs will cope with a warmer world. Responses might depend on the corals' life histories and local environmental conditions. "Global warming will result in more heat-stress events," he says, but "there is accumulating evidence that corals do acclimate".
Before the extreme 2016 incident, global coral bleaching had been observed just twice: in 1998 and 2002. Coral colonies can recover from such events, especially given ò that the species most susceptible to dying from heat stress are among the fastest-growing corals. But harmful warming events are occurring more frequently, and scientists think that full recovery is becoming increasingly difficult ${ }^{2}$.

Researchers have also found that local protection of reefs and surrounding waters does little to make corals less sensitive to heat ${ }^{3}$. Rather, global changes such as ocean acidification might further increase environmental stress.

The fate of tropical coral reefs - including the iconic Great Barrier Reef - therefore depends on efforts to mitigate climate change, says Graham. "A future with coral reefs, their rich diversity and the livelihoods they provide to people is quite simple. It will only be possible if carbon emissions are rapidly reduced," he says.

But even if that happens, tomorrow's reefs might look different from today's, as the mix of species changes in favour of those that can best cope with inevitable climate change, says Hughes. "This transition is already under way, faster than many of us expected," he says. "The Great Barrier is shifting radically, a trend that will continue for the next century or more." -

\footnotetext{
1. Hughes, T. P. et al. Nature https://doi.org/10.1038/ s41586-018-0041-2 (2018).

2. Hughes, T. P. et al. Science $359,80-83$ (2018).

3. Hughes, T. P. et al. Nature 543, 373-377 (2017).
}

\section{East Asia braces for surge in deadly tick-borne virus}

\section{Rapid rise in number of infections concerns researchers.}

\section{BY DAVID CYRANOSKI}

$\mathrm{I}$ nfectious-disease experts in East Asia are preparing for this year's wave of a lethal tick-borne virus. The virus causes a disease called severe fever with thrombocytopenia syndrome (SFTS), which has affected a rapidly growing number of people since it emerged nearly a decade ago.

Scientists in the region say they are worried by the rising incidence of the disease, and by signs that the virus can spread more easily than previously thought. In March, Japan launched the first clinical trial of a drug to treat the infection, and some researchers say that governments should devote more resources to raising awareness and studying the virus.

"It is our responsibility to come up with an effective treatment," says Masayuki Saijo, a virologist at the National Institute of Infectious Diseases in Tokyo, who helped to launch the trial.

Cases of SFTS were first reported in China in 2009 (X.-J. Yu et al. N. Engl. J. Med. 364, 1523$1532 ; 2011)$. Researchers identified the virus responsible in blood samples from a cluster of people who shared a combination of symptoms, including high fever, gastrointestinal problems, low white blood cell count and low platelet count (thrombocytopenia).

The virus killed $30 \%$ of those infected in China that year. It was even more lethal when the first cases appeared in Japan and South Korea in 2013. More than one-third of those infected in Japan and nearly half of those infected in South Korea died that year.

And the number of cases in each country has risen sharply. In 2013, there were 36 reported cases in South Korea; by 2017, the number had jumped to 270. In 2010, China reported 71 cases; in 2016, there were around 2,600. Japan experienced a 50\% 